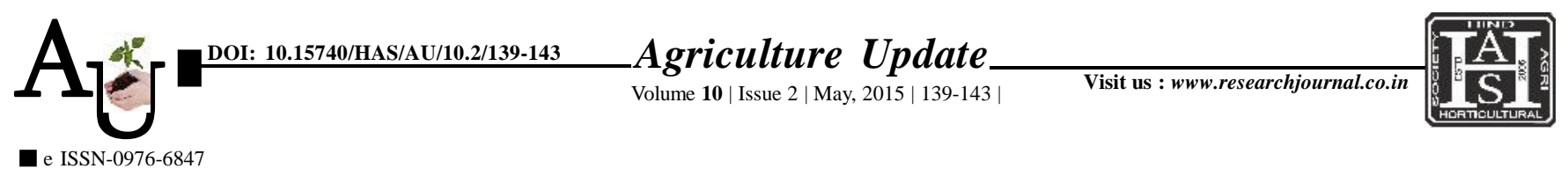

\title{
Research Article: Test to measure knowledge level of trainers on andragogy
}

\section{U. BARMAN}

Article Chronicle: Received :

09.03.2015;

Revised :

24.03.2015;

Accepted :

09.04.2015

KeY Words :

Andragoy,

Knowledge test, Trainers, Facilitators

Author for correspondence :

\section{U. BARMAN}

Department of Extension Education, Faculty of Agriculture, Assam Agricultural University, JORHAT (ASSAM) INDIA

Email: barman.utpal@ gmail.com programme.
SUMMARY : Training is an important activity of human resource development. It is an adult education enterprise. Therefore, characteristics of trainees or adult learners need to be considered by the trainers while conducting training. Therefore, it is necessary for the trainers to possess good knowledge on andragogy. The trainer should act as a facilitator while conducting training. Knowledge on andragogy is an important component of facilitation skills. It helps trainers to conduct the training programme productively. Therefore, it is important to know the level of knowledge of trainers on andragogy. However, little effort is given in this aspect by the training organisation. On the other hand, there is no test readily available to measure the knowledge level of trainers on andragogy. It was thought necessary to construct a test to measure the knowledge level of trainers on andragogy. Therefore, an attempt has been made to develop a knowledge test in this regards. Initially, 60 items were collected and these were examined through 20 experts for its suitability to retain in the knowledge test. Finally, 42 items were taken for item analysis and that was done with the help of 60 trainers. Both indexes of difficulty and index of discrimination were calculated for the items. After calculating index of difficulty and index of discrimination, 17 items were retained for final knowledge test whose index of difficulty ranged between 0.3 to 0.8 and indexes of discrimination was 0.3 and more. The reliability of the test in terms of KudarRicharson formula $\left(\mathrm{K}-\mathrm{R}_{20}\right)$ was found at 0.73 . The test can be utilised by different training organisation for selection of good facilitators. It also helps to identify the training need of the trainers on andragogy, the result of which can be useful to design need based training modules for the trainers training

How to cite this article : Barman, U. (2015). Test to measure knowledge level of trainers on andragogy. Agric. Update, 10(2): 139-143. 